\title{
O ENSINO DE QUÍMICA ATRÁVES DE UM CENTRO DE CIÊNCIAS AMAZÔNICO: UMA POSSIBILIDADE DE INSERÇÃO À CULTURA CIENTÍFICA
}

\author{
TEACHING CHEMISTRY THROUGH AN AMAZON SCIENCE CENTER: A \\ POSSIBILITY OF INSERTION TO SCIENTIFIC CULTURE
}

Francisco Everdosa Tolosa ${ }^{1}$

ORCID iD: $\underline{0000-0001-5373-0443}$

André Silva dos Reis ${ }^{2}$

ORCID iD: 0000-0003-2202-7434

Maria Dulcimar de Brito Silva ${ }^{3}$

ORCID iD: 0000-0001-5556-6173

\section{RESUMO}

A pesquisa buscou relatar e debater através de enfoque qualitativo, de caráter exploratório, atividades desenvolvidas durante um "Dia Temático de Química" no Centro de Ciências e Planetário do Pará (CCPP), com alunos do $3^{\circ}$ ano do Ensino Médio de uma Escola da Rede Pública de Ensino de Belém (PA). Na ocasião, os estudantes participaram de práticas experimentais, com vistas, a verbalizar ideias e a responder um questionário direcionado as atividades realizadas, bem como, fazer considerações sobre a proposta do "Dia Temático". A análise dos resultados revela que a atividade foi relevante para os alunos, pois se sentiram confortáveis na exposição de ideias a respeito de alguns conceitos químicos, o que colabora na construção de novas concepções em relação a essa Ciência. Do mais, verificou-se que o CCPP, um espaço não formal de ensino, pode contribuir no processo de alfabetização científica.

Palavras-chave: Ensino de Química. Alfabetização Científica. Centro de Ciências.

\begin{abstract}
The research sought to report and discuss, through a qualitative approach, of an exploratory character, activities developed during a "Thematic Day of Chemistry" at the Science Center and Planetarium of Pará (CCPP), with students of the 3rd year of High School of a School of the Public Education Network

\footnotetext{
${ }^{1}$ Licenciado em Química pela Universidade Federal do Pará (UFPA). Colaborador de Química do Centro de Ciências e Planetário do Pará (CCPP/UEPA), Belém, Pará, Brasil, Av. Augusto Montenegro, s/n - Km 03 Mangueirão, 66.640-000. E-mail: pesquimica04@ gmail.com.

${ }^{2}$ Mestre em Química pela Universidade Federal do Pará (UFPA). Técnico Educacional de Química do Centro de Ciências e Planetário do Pará (CCPP/UEPA), Belém, Pará, Brasil, Av. Augusto Montenegro, s/n - Km 03 Mangueirão, 66.640-000. E-mail: andre.reis@uepa.br.

${ }^{3}$ Mestre em Química pela Universidade Federal do Pará (UFPA). Professora Assistente IV da Universidade do Estado do Pará (UEPA). Membra do grupo de Ciência, Tecnologia, Meio Ambiente e Educação Não-Formal (CTENF) do Centro de Ciências e Planetário do Pará (CCPP/UEPA), Belém, Pará, Brasil, Rua do Una, 156 Telégrafo, 66050-540. E-mail: mariadulcimar@gmail.com.
} 
of Belém (PA). On the occasion, the students participated in experimental practices, with a view to verbalizing ideas and answering a questionnaire directed to the activities carried out, as well as making considerations about the "Thematic Day" proposal. The analysis of the results reveals that the activity was relevant for the students, since they felt comfortable in the exposition of ideas about some chemical concepts, which collaborates in the construction of new conceptions in relation to this Science. Furthermore, it was found that the CCPP, a non-formal teaching space, can contribute to the process of scientific literacy.

Keywords: chemistry teaching. scientific literacy. science center.

\section{ENSINO DE QUÍMICA ARTICULADO AO ESPAÇO NÃO FORMAL}

Ao longo das últimas décadas, autores como Cazelli, Marandino e Studart (2003), Marandino (2005), Jacobucci (2008) e Rocha e Terán (2013) têm ressaltado a necessidade de olhar os espaços não formais como ambientes de relevância ao ensino de ciências, por considerar que a concepção de educação tem sido ampliada. Além dos saberes da mediação que podem ser desenvolvidos nesses espaços, conforme destacam Queiroz et al. (2002).

A escola, instituição central de educação formal, vem sendo alvo de inúmeros debates, os quais tem enfatizado a necessidade de reformulação de suas práticas de ensino, porquanto não tem conseguido ensinar aspectos mais abrangentes dos conhecimentos científicos a população. Nesse contexto, os Museus, os Centros e os Clubes de Ciências se constituem como ambientes que podem contribuir na diversificação de processos democráticos de inclusão sóciocientífica. É possível expressar um modelo que sintetiza as relações dentro dos ambientes não formais (esquema 1), com as devidas ressalvas, no qual a mediação tem papel de suma relevância.

Outro ponto a destacar é que a utilização desses locais pode causar, no visitante, estímulos em favor do aprendizado e desenvolvimento dos saberes da mediação humana e, por sua vez, do fortalecimento da cidadania, pois o possibilita ter uma leitura científica do mundo. Ao considerar então, um caminho relevante a aquisição de conhecimentos relativos à Ciência, observa-se nas ações educativas em espaços não formais de ensino, uma forma de propiciar, a partir de variadas situações, maior dinâmica a correlação ensino e aprendizagem (JACOBUCCI, 2008). 


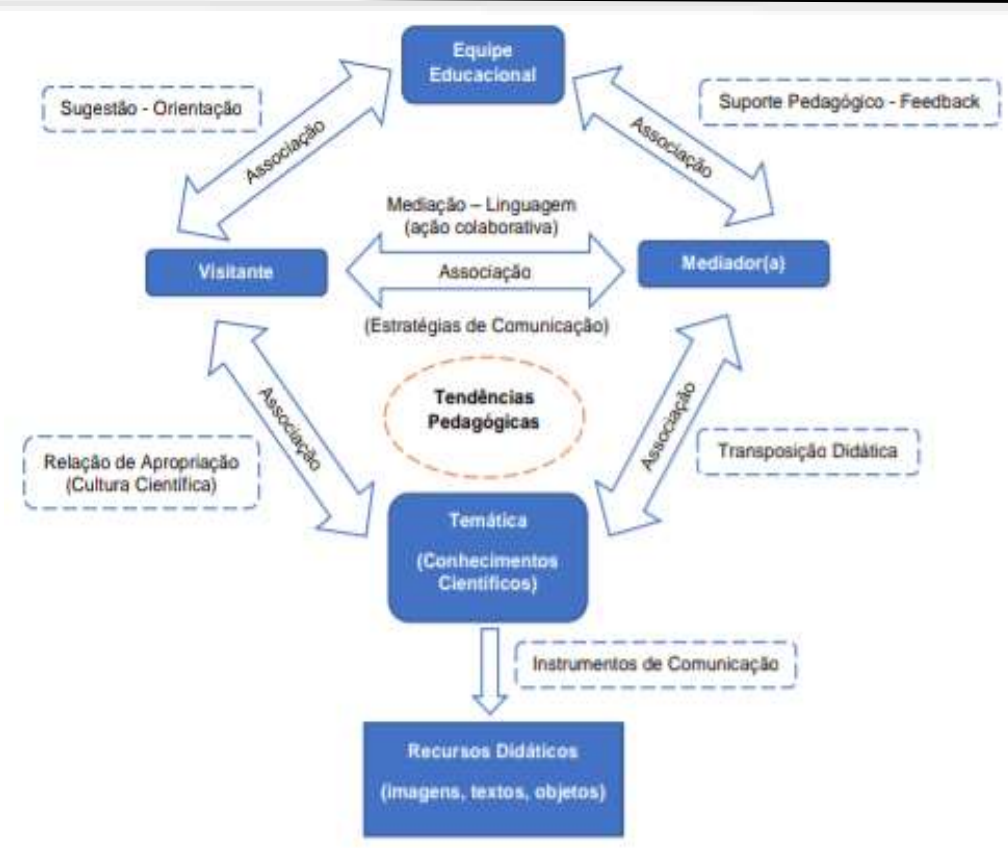

Esquema 1 - Relações comunicativas na educação não formal Fonte: Autoria própria (2019).

Ao longo das últimas décadas, as pesquisas voltadas ao ensino de química têm enfatizado a necessidade de promover atividades que possam reconfigurar a percepção dos conhecimentos químicos no seio social, nisso temos a destacar os trabalhos de Mortimer e Miranda (1995); Lopes (1995); Ferreira, Hartwig e Rocha-Filho (1997); Zuliani (2006) e Ferreira. Hartwig e Oliveira (2010). Outros trabalhos como o de Santos (2004), Wartha e Rezende (2011) e Taborda e Penha (2014) pontuam sobre os eixos comunicativos da química e o que deve ser melhorado no ensino dessa ciência.

Corrobora com essa visão, o ensino de química pautada em memorizações de informações, de fórmulas e de nomenclaturas, em detrimento de práticas abrangentes que focalizem, por exemplo, o entendimento dos conceitos químicos. Nesse sentido, torna-se conveniente uma melhor divulgação dos conhecimentos dessa ciência.

Ao olhar para os espaços não formais temos que a Química é a que possui "menor representatividade'” (PALMIERI, 2018, p. 20). Estudos relacionados a essa dimensão educativa têm ressaltado que as instituições não formais dedicadas a ensinar e divulgar os conhecimentos químicos têm se dedicado, em muitos casos, ao espetáculo. Para Frohlich e Silva (2017, p. 180) há necessidade de se rever a abordagem química nesses locais:

Em vários dos casos, ao frequentarmos museus de ciências, notamos que quando há algum módulo dedicado à Química, a abordagem é pautada na espetacularização, com realização de experimentos com mudança de cor, explosões, em espaços que nos 
remetem à ideia de um laboratório. Com isso, podemos reforçar alguns estereótipos e concepções equivocadas sobre essa Ciência, no processo de construção de conhecimento e como a comunicamos.

O modo muitas vezes arcaico com que o ensino de Química é tratado na educação básica do Brasil, principalmente na Região Norte, é um dos fatores que têm dificultado sua aprendizagem. Estando na contramão de trabalhos que vêm sendo executados em outros locais, os quais incorporaram as práticas de ensino temáticas voltadas a relação concreta da vida em sociedade, fundamentando a construção de conhecimentos na Perspectiva CTS - Ciência, Tecnologia e Sociedade, ou em atividades construtivas de experimentação com materiais de fácil aquisição, que são marcadas por uma sequência problematizada de ensino. Ademais é possível a utilização da História da Ciência como ponto esclarecedor de aspectos representacionais.

Diante disso, objetiva-se pela pesquisa expor e discutir o desenvolver do ensino de Química mediante sequência didática introduzida em um "Dia Temático", no Centro de Ciências e Planetário do Pará (CCPP), espaço não formal de divulgação e popularização da Ciência, como modo de inclusão social, por meio da exposição e de atividades educativas diversificadas, e de contribuição no processo formacional de profissionais da educação e das demais áreas do conhecimento científico com base na relação comunicativa: equipe técnica disciplinar-mediador-visitante-espaço.

O modelo relacional apresentado explicita caminhos comunicativos da educação não formal. Nisso temos que, a equipe técnica disciplinar fica responsável por prestar o devido apoio aos mediadores (geralmente futuros professores) no que tange a maneira de realizar a mediação ao visitante, expor a mensagem (intenção) que se deseja transmitir pela linguagem, exposição e estruturação dos ambientes da instituição. A equipe técnica disciplinar também compete à orientação inicial sobre a condução da visita, assim como, o recebimento de sugestões acerca de melhoramentos que possam ser realizados.

Ao mediador cabe a responsabilidade de estabelecer a comunicação entre o visitante e o conhecimento cientifico, isto é, a transposição didática. Outro ponto, a considerar é que são propagadores da proposta da instituição, isto deve ser bem presente no ato comunicacional. Devem ser regularmente instruídos pela equipe técnica no intuito de aperfeiçoar a mediação. Temos que os mediadores são colaboradores fundamentais na apropriação de conhecimento 
pelos visitantes uma vez que estabelecem um elo entre o público e temática abordada, para tanto, pode ser usado textos, imagens e objetos.

\section{A PRÁTICA EDUCATIVA NO CAMINHO DO ESPAÇO NÃO FORMAL}

Ao buscar na literatura científica pesquisas direcionadas a espaços não formais de ensino, tem-se que a primeira instituição na história que se assemelha na característica de um espaço não formal é o Museu de Alexandria. Isso se deve a maneira como era protagonizado o processo de ensino naquela época, o qual era marcado por uma visão integrada do conhecimento, de modo a possibilitar que, os aprendizes pudessem discorrer das mais variadas formas sobre os fenômenos da natureza e aspectos da vida em sociedade, era basicamente uma comunidade de pesquisadores (GASPAR, 1993).

O surgimento de museus públicos ocorreu nos séculos XVII e XVIII, como consequência do crescente interesse de parcela considerável da população europeia pelas Ciências e pela Cultura. Assim, como forma de organizar o conhecimento até então produzido e dar acesso a população é cogitado por influentes filósofos entre os quais se destacam Francis Bacon e René Descartes, a criação de locais que exibissem invenções da humanidade. Essa ideia é compartilhada pelo filosofo e matemático alemão, Wilhelm Leibniz, o qual propôs a exposições de máquinas e de outras invenções, para fins de esclarecer e entreter ao públicovisitante.

O entreter ficaria por conta da realização de demonstrações experimentais com água, ar e o vácuo, realização de testes como os maquinários expostos, além da exibição de plantas raras e de painéis contendo a anatomia humana. Isso só se torna concreto no final do século XVII (1683), mediante a doação de Elias Ashmole de sua coleção de maquinários à Universidade de Oxford, surgindo assim, o primeiro museu público de que se tem notícia, o qual foi batizado de Museu Ashmoleano (GASPAR, 1993). E no século seguinte abriu-se o segundo museu, que ficou conhecido como Museu Britânico. Sendo a partir disso, criado uma série de novos museus.

É necessário salientar que o uso da expressão "Museu de Ciências" só vem a ser empregada em 1909, com a separação das coleções de artes e decoração. A educação daí em diante torna-se o foco central dos museus e, não mais a simples exposição de objetos históricos. Tendo Estados Unidos como um dos principais países a dar início ao processo de divulgação científica através dos museus, dando ênfase em museus de história natural. 
Cabe ressaltar que havia a preocupação em se desligar de um padrão elitista e tornar os museus de fácil acesso e evidenciar a difusão científica a todas as classes sociais. Muitos museus de ciências acabam adotando a denominação de "Centros de Ciências" e de denominações similares. Sendo em 1973, criado nos EUA a Associação dos Centros de Ciência e Tecnologia (ASTC), objetivando propiciar subsídios prático-teóricos e a promoção de atividades cooperativas entre instituições dessa natureza (GASPAR, 1993).

Os modelos implementados nos Centros de Ciências estadunidense foram sendo disseminados por outros países. Tendo como pilares da divulgação científica a síntese do conhecimento e a capacidade de colaborar com os aprendizes mediante interações sensoriais (ver, tocar, sentir), buscando leva-los a ter autonomia no pensar e, consequentemente, no agir. Auxiliando, desse modo, a estabelecerem conexões com situações de sua vida cotidiana. Para Gruzman e Siqueira (2007, p. 403):

\footnotetext{
No âmbito dos museus de ciência - que outrora se apresentavam principalmente como locais de acondicionamento de objetos - sua articulação com a sociedade se intensifica a partir de uma preocupação com a educação e a divulgação científica e o seu comprometimento com a compreensão pública da ciência.
}

No Brasil, os Museus de Ciências até então conhecidos como Museus de História Natural tem sua criação em 1818 através de D. João VI. Na ocasião foi chamado de Museu Real, hoje rebatizado de Museu Nacional (RIBEIRO, 1987). Com o passar do tempo foram surgindo novos museus, sendo que a partir da promulgação da Lei das Diretrizes e Bases da Educação Nacional, o então Ministério da Educação e Cultura cria o Projeto de Expansão e Melhoria do Ensino (PREMEN), o que impulsionou a elaboração de materiais didáticos voltados ao ensino de ciências e a promoção de atividades extraescolar (GASPAR, 1993).

O Estado do Pará foi pioneiro em muitos avanços relativos à diversificação do processo educativo fora dos ambientes da escola. Sendo o Museu Paraense Emilio Goeldi (anteriormente denominado de Museu Paraense) o responsável pela criação em 1985 de uma Divisão de Educação Científica. Um marco para a Região Norte e para o Brasil de maneira geral (GASPAR, 1993).

O fomento na criação de museus e centros de ciências tem sido uma forma que o governo brasileiro tem se utilizado para avançar no que tange políticas públicas de inclusão social, fato que é destacado por Marandino (2017, p. 811): 
Editais de popularização da ciência lançados pelo anteriormente chamado Ministério da Ciência e Tecnologia (hoje Ministério da Ciência, Tecnologia, Inovações e Comunicações), em parceria com outros órgãos, como o Conselho de Desenvolvimento Científico e Tecnológico ( $\mathrm{CNPq}$ ) e a Academia Brasileira de Ciências $(\mathrm{ABC})$, com empresas privadas e fundações (por exemplo, a Fundação Vitae), e pelas Fundações de Amparo à Pesquisa dos estados (FAPs) foram cruciais para a inauguração de museus e centros de ciências em várias regiões do país e para a estruturação e diversificação das atividades já existentes.

Diante disso, é imprescindível ser abordado à importância do Centro de Ciências e Planetário do Pará (CCPP), como espaço não formal de educação. O CCPP, anteriormente denominado de Planetário do Pará ' Sebastião Sodré da Gama', foi inaugurado no ano de 1999, com o propósito de difundir a Astronomia no Estado do Pará. A denominação Sebastião Sodré da Gama é uma homenagem a esse matemático paraense responsável pela direção do Observatório Nacional, no período de 1930 a 1951, e membro do Núcleo Fundador da Sociedade Brasileira de Ciências, hoje Academia Brasileira de Ciências (ABC).

A partir de 2012 com a remodelagem de sua estrutura física, a instituição passou a ser constituída pelos ambientes de: Física, Geologia, Biologia, Astronomia, Matemática e Química. Além de sua cúpula Kwahary, termo indígena que significa Sol em tupi-guarani. A escolha desse nome se deu por aludir uma proposta de conexão com a energia emanada pelo Sol, seria uma forma simbólica de expressar uma trajetória de luz ao CCPP.

A mediação em um ambiente não formal de ensino, como o do Centro de Ciências e Planetário do Pará (CCPP), pode contribuir na diversificação do processo de ensino e aprendizagem e na formação inicial de professores, pois, permite aos licenciandos uma maior mobilidade na apresentação dos conhecimentos científicos, o que acaba por ajudar na linguística, percepção, diversificação, adaptação, preparo e evolução constante na labuta de um profissional da educação. Além de possibilitar atividades de reflexão e pesquisas educativas. Sendo necessário, dar-se maior atenção a atividades de formação em espaços não formais de ensino, no que tange estudos.

Essa concepção de science centers como ficou conhecido os museus de ciências da terceira geração, os quais passam a contemplar as práticas educativas, buscam alinhar modelos e ferramentas tecnológicas através de variadas ações comunicativas. Nesse contexto, o olhar dos visitantes passa a centrar as práticas desenvolvidas, com os objetos de cunho histórico sendo foco secundário (GRUZMAN; SIQUEIRA, 2007).

É necessário ressaltar que diferentemente do EUA em que os museus e centros de ciências são originários da iniciativa privada, no Brasil ocorre o contrário, as instituições 
governamentais é que acabam por desenvolver esses ambientes, as quais geralmente são vinculadas a Academia ou a Instituições de pesquisa. Um exemplo disso é o Museu Biológico do Instituto Butantan, criado em 1957 e o Centro de Ciências e Planetário do Pará vinculado a Universidade do Estado do Pará (UEPA), inaugurado em 1999, voltado ao ensino de Astronomia. Sendo reinaugurado em 2012, após remodelagem de seu ambiente, devido à expansão de sua ação educativa.

Para fins de compreensão é válido salientar que a Associação Brasileira de Centros e Museus de Ciências (ABCMC) trata de maneira equivalente as expressões museus de ciências e centros de ciências, ponto que corrobora com percepção de europeus e de estadunidenses. Nesse trabalho preferiu-se tratá-los distintamente por entendê-los como espaços não formais de ensino que apresentam configurações educativas e arquitetura diferentes, tendo em vista, sua instalação e difusão no contexto brasileiro.

\section{METODOLOGIA}

A atividade ocorreu no Centro de Ciências e Planetário do Pará (CCPP/UEPA), por meio do "Dia Temático de Química", contou com a participação de 21 alunos da terceira série do ensino médio de uma escola pública de Belém (PA). O estudo tem enfoque qualitativo, de caráter exploratório, em que se buscou articular o espaço não formal e o ensinar química. Foi desenvolvida em quatro momentos, com a questão-foco direcionada ao entendimento de "Reação Química" pelos indivíduos participantes da atividade.

O momento inicial destinou-se ao questionamento a respeito da compreensão dos participantes da pesquisa acerca reação química. Após isso, reservou-se o segundo momento a elucidações teóricas necessárias, para fins de subsidiara execução dos experimentos. O procedimento experimental, terceira etapa da atividade, foi efetuado com os kits da Experimentoteca do CCPP, cedidos pelo Centro de Divulgação Científica e Cultural da Universidade de São Paulo (CDCC-USP), referente às temáticas Soluções e Cinética Química. Os estudantes foram separados em seis grupos, os quais incluíam de três a quatro integrantes. Tiveram como suporte um guia esquematizado com vistas a auxiliá-los no decorrer da atividade.

Depois, no quarto e último momento, promoveu-se experimento com o uso de materiais alternativos com o intuito detratar sobre o deslocamento do equilíbrio químico. Para isso, tevese como referência o trabalho de Ferreira, Hartwig e Rocha-Filho. (1997), com adaptações no que se refere a abordagem experimental. 
Após a realização do experimento de equilíbrio químico, os mediadores da atividade realizaram considerações em relação ao questionário repassado, o qual continha oito perguntas subjetivas e objetivas que versaram de pontos inerentes as Soluções, a Cinética Química e ao Equilíbrio Químico, além da maneira de abordagem dos temas, pretendendo-se, desse modo, avaliar o método aplicado.

Ademais, foi acordado com os alunos e professores responsáveis pela supervisão da turma que as identidades dos participantes do estudo seriam preservadas. Com uso de Z1, Z2, Z3 e assim sucessivamente, na exposição da autoria das respostas. Para mais, autorizou-se a captação de imagens da atividade, com a execução de desfoque das faces dos indivíduos.

\section{ANÁLISES E RESULTADOS}

O evento valorizou conhecer de início, através de sondagem prévia, as concepções dos estudantes acerca de reações químicas, temática que serviu como âncora para a abordagem dos conceitos posteriores (Figura 1).

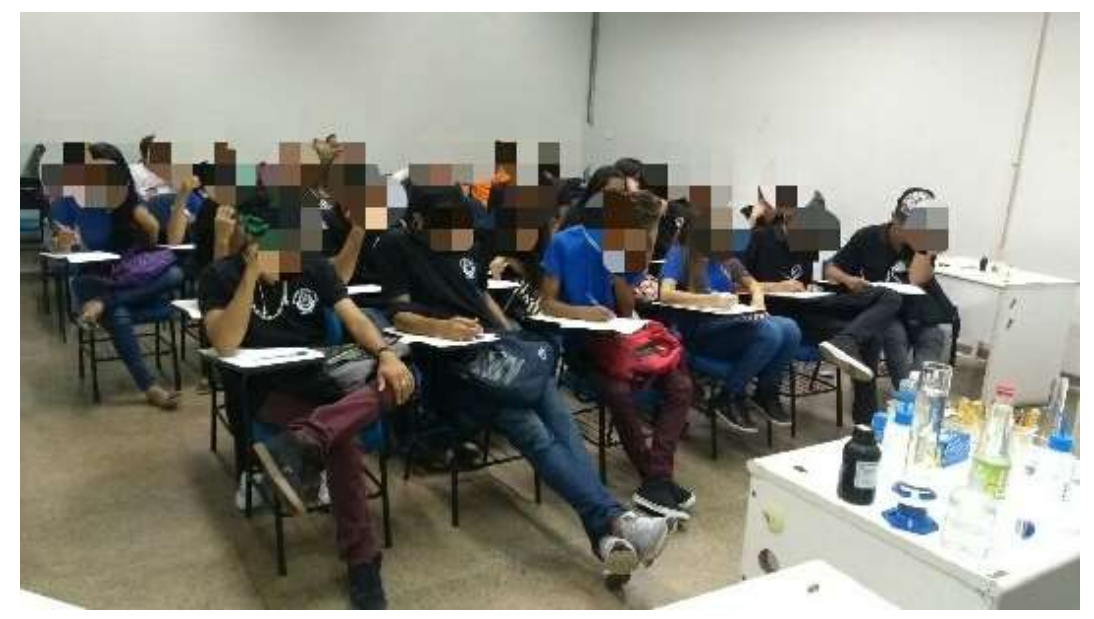

Figura 1 - Sondagem prévia sobre reação química Fonte: Autoria própria (2017).

A partir das respostas à primeira pergunta proposta, a qual está discriminada abaixo, foi possível situar as considerações iniciais dos 21 participantes da pesquisa em três categorias:

\section{1) O que você entende por Reação Química?}

I) Reação Química = Mistura de Substâncias: Para cerca de doze alunos, as reações químicas podem ser entendidas como uma mera mistura de substâncias que ao final formaram um 
produto (uma nova substância). Alguns referiram-se ao acender um fósforo como exemplo da ocorrência de uma transformação química. O predomínio de respostas dessa natureza pôde ser observado em:

"A Reação química é o resultado de uma mistura de elementos, pode ocorrer durante o dia a dia, e pode ter velocidade acelerada ou reduzida e que depende da situação" (Z1).

"Quando dois ou mais elementos reagem forma produtos, temos uma reação química" (Z4).

A maioria dos estudantes demonstrou em suas respostas que qualquer mudança visual (macroscópica) deve ser compreendida como uma transformação química, mesmo que, por exemplo, a dissolução e a mudança de estado de agregação sejam processos físicos que alteram o aspecto visual do sistema. Essas mudanças foram perceptíveis ao longo das práticas experimentais empregadas para exemplificar como se processa a reação química e quais seriam as características reais, como pode ser visto na Figura 2, que apresenta os alunos durante o processo de investigação das reações químicas, propostas pelos monitores (mediadores).
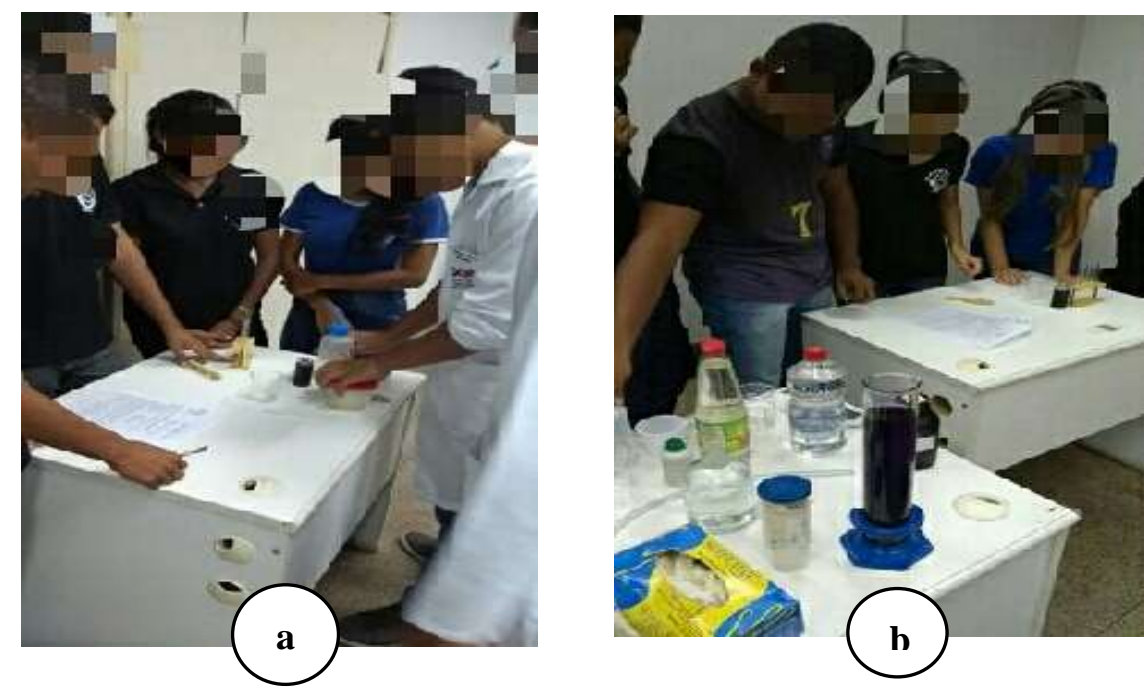

Figura 1 - a) Esclarecimentos sobre a atividade; b) Realização da experimentação.

Fonte: Autoria própria (2017).

Segundo Mortimer e Miranda (1995) os principais obstáculos pelos quais os alunos do ensino fundamental e médio enfrentam ao estudarem aspectos inerentes as reações químicas estão associadas à grande amplitude e generalidade desse conceito. Esses mesmos autores ainda destacam que a maioria dos alunos não consegue identificar similaridades na ocorrência das transformações químicas que possuem características notavelmente bem diferenciadas. 
A dificuldade em ultrapassar o campo das percepções conduz muitas vezes os estudantes a não atentarem para o papel de reagentes e produtos não tão evidentes em uma transformação química é o caso, por exemplo, dos gases. Esse fato, geralmente, ocorre porque a Química é concebida por muitos indivíduos como abstrata, o que não é verdade. Sendo, desse modo, preciso salientar que tal Ciência não pode ser considerada abstrata, mas, pelo contrário, faz parte de nossas rotinas diárias, além de ser de suma importância para nossa sobrevivência, posto que uma série de reações químicas estão sendo constantemente processadas em nosso corpo.

Sem esses necessários esclarecimentos, torna-se difícil para uma pessoa querer compreender aspectos relativos as reações químicas. Sendo, de certo modo, preocupante posto que esse conceito "representa o cerne da química" (TABORDA; PENHA, 2014, p. 57).

A não compreensão de reações químicas implica em uma série de dificuldades no estudo de conceitos posteriores, pois o comportamento da matéria concentra-se basicamente nesse eixo conceitual.

II) Reação Química - Nível Macroscópico X Nível Microscópico: Em relação a essa categoria, verificaram-se seis considerações nessa linha de raciocínio. Os estudantes concebem o nível macroscópico (fenomenológico) como se fosse uma extrapolação do nível microscópico (atômico-molecular), isto é, evidenciam que aquilo que é aplicável ao macro também se aplica ao micro, conforme relatos abaixo:

"Reações Químicas fazem parte do nosso dia-a-dia, quando vemos uma banana amadurecer, quando acontece a oxidação do ferro" (Z1).

“As reações são muito importantes, pois permitem a criação e fabricação de produtos diversos” (Z2).

A falta de limite entre o que se observa e as explicações e representações tem sido um grande entrave ao ensino da Química, visto que não é discutido com os alunos o papel de cada componente da tríade química - fenômenos, teorias e modelos e representações - para uma melhor compreensão dessa ciência. Isso acaba dificultando a construção do entendimento de conceitos químicos fundamentais como, por exemplo, o de substância.

No que se refere ao eixo fenomenológico é preciso evidenciar aos alunos o foco de interesse da Química, no que diz respeito a um dado fenômeno. É por conta disso, que autores como Mortimer e Miranda (1995) destacam que um dos aspectos que prejudica a compreensão desse eixo em sala aula é a falta de esclarecimentos passo a passo sobre o processamento de um 
fenômeno químico, como isso não vem ocorrendo, os estudantes acabam dando um sentido real as fórmulas e as equações químicas e, por conseguinte, aos modelos idealizados de átomos.

O professor deve enfatizar que o eixo teórico corresponde a interpretação das informações experimentais, desse modo, deve ser esclarecido que os modelos propostos são hipotéticos, e tentam descrever aquilo que não é possível de ser visualizado, mas que possuem indícios de existência como os átomos, as moléculas, os elétrons. O eixo representacional é a descrição da linguagem química, sendo feito mediante equações e fórmulas químicas, representações de modelos, gráficos e expressões matemáticas. É válido discutir com os alunos no que diz respeito as equações químicas, aspectos que dão suporte a representação relativos a reação, como trocas de energia, evidenciando que elas possuem distintas taxas, as quais dependerão de fatores como concentração, estados físicos e natureza dos reagentes, temperatura do ambiente em que se está processando a reação química, além da superfície de contato (MORTIMER; MIRANDA, 1995).

As autoras Wartha e Rezende (2011) em seus escritos sobre a semiótica acabam por reforçar as concepções tratadas acima ao apresentarem o modelo esquematizado por Johnstone acerca dos níveis de conhecimento químico, destacando: o nível descritivo e funcional (macroscópico), o nível simbólico (representacional) e o nível explicativo (microscópico).

III) Reações Químicas - Equações e Classificações: Houve três respostas em que ocorreu a ilustração de equações químicas, considerando-as como reações químicas e não como representações da reação. Além da utilização de classificações tradicionais para a abordagem de uma transformação química. As equações esquematizadas não discriminaram os estados físicos das substâncias, fazendo com que os fenômenos químicos sejam compreendidos como meros jogos de deslocamentos e de manipulações algébricas.

“Ocorrem vários tipos de reações (análise, dupla troca). É importante controlar, porque são capazes de ocorrer explosões” (Z5).

"Quando dois ou mais elementos reagem geram um produto, há uma reação química. Ex: $H_{2}+O=$ $\mathrm{H}_{2} \mathrm{O}, \mathrm{N}+\mathrm{H}_{3}=\mathrm{NH}_{3}$ ” (Z9).

As equações químicas foram uma forma encontrada de representar uma transformação química, contudo não é dado esse devido esclarecimento aos alunos, o que suscita por parte deles simplificadas classificações das reações em síntese, análise, simples troca e dupla troca. Assim, é valido destacar que a maioria das reações químicas são processadas em solução aquosa, por esse motivo é necessário que ocorra uma mudança de concepção, posto que, ao representar as equações e classificações sem distinção entre meio aquoso e não aquoso, acaba- 
se por seguir o modelo descritivo desenvolvido pelo cientista sueco, Jöns Jacob Berzelius, o qual considera a dualidade dos compostos químicos, baseando-se na sua visão de afinidade e de sua teoria eletroquímica, como forma de explicar a simples troca (1) e dupla troca (2) em uma reação química (LOPES,1995).

$$
\begin{aligned}
& \mathrm{AB}+\mathrm{C} \rightarrow \mathrm{CB}+\mathrm{A} \\
& \mathrm{AB}+\mathrm{CD} \rightarrow \mathrm{AD}+\mathrm{CB}
\end{aligned}
$$

Desse modo, é conveniente entender que a Química passou e passa por evoluções representativas, sendo assim, é preciso atentar para os avanços interpretativos e explicativos que vieram após as sistematizações de Berzelius, como, por exemplo, a Teoria da Dissociação Eletrolítica de Arrhenius e as Teorias das Ligações Químicas. Caso contrário, os alunos entenderam as reações com um apanhado de classificações que devem ser memorizadas e, não a sua amplitude (LOPES, 1995).

As respostas fornecidas evidenciaram a pouca familiaridade dos estudantes em relação ao conceito de reação química. Tal fato, provavelmente, ocorre pelo formalismo dado às classificações no ensino dessa ciência, alicerçadas em abordagens simplistas e, até mesmo errôneas presentes nos livros didáticos, em detrimento de atividades que desenvolvam aspectos conceituais (LOPES, 1995).

Para Zuliani (2006) o entendimento da Química perpassa pela promoção de atividades que estimulem a evolução da concepção dos alunos e discussões acerca de suas explicações a dados fenômenos, visto que, muitas de suas ideias referentes à Química estão associadas a histórias em quadrinhos, que apresentam essa ciência relacionada a explosões, laboratórios e substâncias coloridas. Sendo que, essa forma representativa não contempla a magnitude da Química.

Segundo Santos (2004) os conhecimentos científicos vêm sendo ensinados aos alunos como se fossem uma coleção de fatos isolados, em que as descrições de fenômenos e os enunciados teóricos são vistos como meras informações a serem decoradas. A imensa dificuldade em se realizar a contextualização dos conhecimentos químicos em sala de aula decorre de vários fatores, dentre os quais, destaca-se a desvalorização das representações que os alunos trazem sobre o mundo ao seu redor. Essas descrições, caso sejam devidamente consideradas podem ser de grande valia, pois servirão como ponto de partida para a demonstração de como os conhecimentos científicos são estabelecidos.

Após a sondagem e as explicações teóricas sobre as temáticas abordadas teve início a experimentação. A parte procedimental começou com o entendimento de aspectos inerentes a soluções, tais como: solubilidade das substâncias, fatores que afetam a solubilidade de uma substância e classificação das soluções em insaturada, saturada e supersaturada. Neste ponto, observou-se os estudantes bem entusiasmados, em decorrência do protagonismo exercido. 
Para Queiróz et al. (2002), a relação afetiva é um aspecto que deve ser considerado como diferencial nas mediações realizadas em ambientes não formais. Esse aspecto foi de grande valia durante todo o transcorrer da experiência. Os próprios alunos executaram os procedimentos experimentas, podendo, dessa forma, visualizar na prática como ocorre a formação de uma solução. Além disso, foi possível esclarecimentos de muitas dúvidas que os afligiam sobre aspectos relativos a insaturação, saturação e supersaturação, sobretudo, no que tange ao corpo de fundo (precipitado) formado póssaturação e o papel da temperatura na determinação classificatória de uma solução.

Há diversas estudos voltados a aplicação desses métodos mais integrativos no ensino de Química, destaca-se o repertório variado de pesquisas publicadas tanto em revistas nacionais como internacionais, sendo que muitas delas estão ao alcance de qualquer profissional que queira fazer com que a sua prática educativa torne-se, de fato, relevante para aos seus alunos, não sendo plausível argumentações que objetivam a continuidade de modelos de ensino engessados.

É necessário frisar que os pesquisadores, na ocasião, serviram como mediadores na construção do saber científico, posto que, a experimentação em si pode não contribuir à promoção da aprendizagem (FERREIRA; HARTWIG; OLIVEIRA, 2010). Ao término dessa primeira atividade experimental os alunos foram convidados a responderem algumas questões propostas, as quais vão ao encontro do que foi executado. A partir das respostas, percebeu-se que os estudantes apresentaram melhores noções a respeito dos conceitos abordados.

A experimentação relativa à temática cinética química teve como objetivo a compreensão ampla desse tema, sendo os pontos destacados a aceleração e o retardamento das reações, direcionados para situações cotidianas desses alunos, envolvendo por exemplo a pintura de um portão de ferro, o apodrecimento das frutas, o amadurecimento de bananas muito verdes e a corrosão provocada pela maresia. Nessa altura, teve-se o cuidado de familiarizar os alunos com algumas substâncias e suas composições químicas, além de serem feitas colocações acerca dos procedimentos. Ademais, foram analisados pelos alunos sob a ótica dos mediadores certos fatores que alteram a velocidade das reações como a concentração dos reagentes, a temperatura e a superfície (ou área) de contato.

É válido destacar, que em nenhum momento utilizou-se de materiais sofisticados e de reagentes de difícil aquisição, pelo contrário, foram usados materiais de fácil acesso. Essa é uma das máximas de grande relevância nas práticas realizadas no ambiente de Química do Centro de Ciências e Planetário do Pará, local em que há o devido cuidado em tornar a prática de ensino significativa, utilizando-se materiais de baixo custo, sendo uma maneira de inspirar os educadores que visitam o CCPP, em realizar uma abordagem diferenciada da relação ensino e aprendizagem. Muitas das atividades experimentais podem ser executadas até mesmo em sala de aula, caso não haja um laboratório na escola, a qual se é vinculado. Os estudantes foram convidados, após o experimento referente cinética química, a responder algumas questões relativas ao procedimento executado. 
O último experimento realizado foi de caráter demonstrativo, em que os mediadores promoveram o deslocar do equilíbrio químico, visando salientar que o equilíbrio químico é diferente do equilíbrio estático, visto que, é dinâmico. Para isso, usou-se como suporte teórico o trabalho desenvolvido por Ferreira, Hartwig e Rocha-Filho (1997), com modificações na forma de abordagem da experimentação.

O último experimento realizado foi de caráter demonstrativo, em que os mediadores promoveram o deslocar do equilíbrio químico, visando salientar que o equilíbrio químico é diferente do equilíbrio estático, visto que, é dinâmico. Para isso, usou-se como suporte teórico o trabalho desenvolvido por Ferreira, Hartwig e Rocha-Filho. (1997), com modificações na forma de abordagem da experimentação.

De modo geral, o Dia Temático foi bem proveitoso, posto que os estudantes conseguiram desenvolver o entendimento dos conceitos químicos abordados, dentro daquilo que se esperava. É claro que há necessidade de frequente ênfase para a consolidação da aprendizagem de um dado conceito, na ocasião foi possível estabelecer esse primeiro passo. Os alunos verbalizaram que o modo de apresentação dos conhecimentos químicos é bem válido, pois instiga o aprendizado, carece preciso ser bem elaborado e ter um tempo expressivo para sua aplicação.

\section{CONSIDERAÇÕES FINAIS}

Os objetivos propostos foram alcançados, uma vez que os estudantes conseguiram compreender processos inerentes as transformações químicas e, por consequência, como se constrói o conhecimento científico, ao deixar, de lado, certas visões simplistas sobre o desenvolvimento da Ciência.

De modo geral, os resultados obtidos salientam que a química pode ser favorecida em instituições como o Centro de Ciências e Planetário do Pará, desde que o modo de abordar os conceitos científicos não tenha similaridade com o dos programas escolares. Os alunos se 1 sentem à vontade quando possui graus de liberdade, a ação de protagonismo evidenciou essa situação. O Espaço Não Formal de Ensino pode colaborar na inclusão sóciocientífica da população, bem como, auxiliar na diversificação da relação de ensino e aprendizagem.

Foi possível averiguar durante todo o evento temático que momentos como esse são de fundamental importância para que se possa esclarecer aspectos confusos ou não compreendidos sobre um conceito ou de fatores específicos de certo conteúdo. Constatou-se, por exemplo, que 
os participantes da atividade até sabem descrever razoavelmente sentenças matemáticas, entretanto, não compreendem o que de fato aquilo representa em termos práticos. Esse modo de abordagem dos conteúdos químicos acaba por dar a impressão de que tal ciência se resume a fórmulas, equações, regra de três e balanceamentos. Não sendo válido esse tipo de concepção, pois a Química é uma Ciência muito presente em nossa vida. A compreensão dos conhecimentos químicos possibilita uma leitura mais abrangente do mundo, o que pode ajudar esses aprendizes a modificar o meio onde vive.

É por essa razão que práticas como as promovidas pelo CCPP podem provocar maiores estímulos à compreensão de conceitos científicos, fazendo-se questão de destacar que os conhecimentos a serem aprendidos não deve estar distante da realidade dos aprendizes, com objetivo de que se crie familiaridade entre eles e o que se deseja ser ensinado. 


\section{REFERÊNCIAS}

CAZELLI, Sibelli; MARANDINO, Martha; STUDART, Denise Coelho. Educação e comunicação em museus de ciência: aspectos históricos, pesquisa e prática. In: Educação e Museu: a construção social do caráter educativo dos museus de ciências. Editora Access/Faperj, Rio de Janeiro, 2003. p. 83-106. Disponível em: https://edisciplinas.usp.br/pluginfile.php/844165/mod_resource/content/1/CAZELLI_MARA NDINO_STUDART_Educa\%C3\%A7\%C3\%A30_\%20Comunica\%C3\%A7\%C3\%A30_em Museus_de_Ci\%C3\%AAncia.pdf. Acesso em: 20 fev. 2020.

FERREIRA, Luiz Henrique; HARTWIG, Dácio Rodney; ROCHA-FILHO, Romeu Cardozo. Algumas Experiências Simples Envolvendo o Princípio de Le Chatelier. Química Nova na Escola, São Paulo, n. 5, n. 1, p. 28-31, 1997. Disponível em: http://qnesc.sbq.org.br/online/qnesc05/exper1.pdf\&ved=2ahUKEwixreOMh6PoAhUSA9QK HWETDUIQFjAAegQIAxAB\&usg=AOvVaw3SrxvIHWJRi2CjHzkxdQJW. Acesso em: 21 mar. 2018.

FERREIRA, Luiz Henrique; HARTWIG, Dácio Rodney.; OLIVEIRA, Ricardo Cardoso de. Ensino Experimental de Química: Uma Abordagem Investigativa Contextualizada. Química Nova na Escola, São Paulo, v. 32, n. 2, p. 101-106, 2010. Disponível em: http://qnesc.sbq.org.br/online/qnesc05/exper1.pdf\&ved=2ahUKEwixreOMh6PoAhUSA9QK HWETDUIQFjAAegQIAxAB\&usg=AOvVaw3SrxvIHWJRi2CjHzkxdQJW. Acesso em: 21 mar. 2018.

FROHLICH, Fernanda Carolina Colere; SILVA, Camila Silveira da. A Química em espaços de educação não formal: uma análise dos museus de ciências da região sul do Brasil. ACTIO, Curitiba, v. 2, n. 2, p. 178-193, jul./set., 2017. Disponível em: https://www.google.com/url?sa=t\&source=web\&rct=j\&url=https://periodicos.utfpr.edu.br/acti o/article/view/6794\&ved=2ahUKEwiy8cXxhaPoAhXND7kGHT4cBtgQFjAAegQIBxAC\&us g=AOvVaw01-49h5wL_ZmffYxA4eKAh. Acesso em:21 fev. 2020.

GASPAR, Alberto. Museus e Centros de Ciências - Conceituação e Proposta de um Referencial Teórico. 1993. 118 f. Tese (Doutorado em Educação) - Faculdade de Educação, Universidade de São Paulo, São Paulo, 1993. Disponível em: http://www.fiocruz.br/brasiliana/media/gaspartese.pdf. Acesso em: 21 março 2018.

GRUZMAN, Carla; SIQUEIRA, Vera Helena Ferraz de. O papel educacional do Museu de Ciências: desafios e transformações conceituais. Revista Electrónica de Enseñanza de las Ciencias, v. 6, n. 2, p. 402-423, 2007. Disponível em: https://www.arca.fiocruz.br/handle/icict/30907. Acesso em: 23 nov. 2019.

JACOBUCCI, Daniela F. Carvalho. Contribuições dos espaços não-formais de educação para a formação da cultura científica. Em Extensão, Uberlândia, v. 7, n. 1, p. 55-66, 2008. Disponível em: http://www.seer.ufu.br/index.php/revextensao/article/download/20390/10860. Acesso em: 22 set. 2019.

LOPES, Alice Ribeiro Casimiro. Reações Químicas - fenômeno, transformação e representação. Química Nova na Escola, São Paulo, v. 2, n. 2, p. 7-9, 1995. Disponível em: 
http://qnesc.sbq.org.br/online/qnesc02/conceito.pdf\&ved=2ahUKEwiZlqKThKPoAhUKD7k GHQADABMQFjAAegQIBxAC\&usg=AOvVaw1U9A181ATiN8-pd2uLDPZA. Acesso em: 21 mar. 2018.

MARANDINO, Martha. A pesquisa educacional e a produção de saberes nos museus de ciência. História, Ciências, Saúde-Manguinhos, v. 12 (suplemento), p. 161-181, 2005. Disponível em: http://www.scielo.br/scielo.php?pid=S010459702005000400009\&script=sci arttext. Acesso em: 21 março 2018. Doi: https://doi.org/10.1590/S0104-59702005000400009.

MARANDINO, Martha. Faz sentido ainda propor a separação entre os termos educação formal, não formal e informal? Ciência e Educação, Bauru, v. 23, n. 4, p. 811-816, 2017. Disponível em:http://www.scielo.br/scielo.php?pid=S151673132017000400811\&script=sci_arttext.

Acesso em: 12 jul. 2019. Doi: https://doi.org/10.1590/1516-731320170030001.

MORTIMER, Eduardo Fleury; MIRANDA, Luciana Campos. Transformações: Concepções de Estudantes sobre Reações Químicas. Química Nova na Escola, São Paulo, v. 2, n. 2, p. 23-26, 1995.

http://qnesc.sbq.org.br/online/qnesc02/aluno.pdf\&ved=2ahUKEwjk3fG1gKPoAhWWHLkG HbNLBrAQFjAAegQIARAB\&usg=AOvVaw3Iwq-fAPVbjQSoFx7CKKmU. Acesso em: 21 março 2018.

PALMIERI, Luciane Jatobá. Museus de Ciências e o Ensino de Química: Análise praxeológica de uma atividade museal. 2018. 164 f. Dissertação (Mestrado em Educação em Ciências e em Matemática) - Setor de Ciências Exatas, Universidade Federal do Paraná, Curitiba, 2018.2 Disponível em: http://www.exatas.ufpr.br/portal/ppgecm/wpcontent/uploads/sites/27/2018/06/117_LucianeJat ob\%25C3\%25A1Palmieri_Corrigido.pdf\&ved=2ahUKEwjEj4eUgaPoAhV2HrkGHd_xD9cQ FjAAegQIARAB\&usg=AOvVaw3cebDpzPyfb1-0bG6yOhAV. Acesso em: 20 fev. 2020.

QUEIRÓZ, Glória; KRAPAS, Sonia; VALENTE, Maria Esther; DAVID, Érica; DAMAS, Eduardo; FREIRE, Fernando. Construindo Saberes da Mediação na Educação em Museus de Ciências: O Caso dos Mediadores do Museu de Astronomia e Ciências Afins/Brasil. In: Revista Brasileira de Pesquisa em Educação em Ciências, Minas Gerais, v. 2, n. 2, 2002. Disponível em: https://periodicos.ufmg.br/index.php/rbpec/article/view/4144. Acesso em: 22 set. 2019.

ROCHA, Sonia Claudia Barroso; TERÁN, Augusto Fachín. Contribuições de aulas em espaços não formais para o ensino de ciência na Amazônia. Ciência em Tela. Rio de Janeiro, v. 6, n. 2, p. 1-10, 2013. Disponível em: http://files.ensinodeciencia.webnode.com.br/200001226e84f8e948f/2013_Rocha\%20e\%20Fa ch\%C3\%ADnTeran_CONTRIBUI\%C3\%87\%C3\%95ES\%20DE\%20AULAS\%20EM\%20ES PA\%C3\%870S\%20N\%C3\%A30\%20Formais.pdf. Acesso em: 20 fev. 2020.

SANTOS, Marta Silva Magalhães Albuquerque dos. Roleta de Iões: Uma nova aplicação para o ensino de química. 2004. 133 f. Dissertação (Mestrado em Educação Multimídia) Faculdade de Ciências, Universidade do Porto, Porto, Portugal, 2004. Disponível em: http://hdl.handle.net/10216/14331. Acesso em: 27 nov. 2019. 
TABORDA, Jamile Mariano Macedo; PENHA, Maranei Rohers. Desmistificando a Química: Investigação das definições dos estudantes do IFRO sobre o real conceito das Reações Químicas. Educação Por Escrito, Porto Alegre, v. 5, n. 1, p. 51-67, 2014. Disponível em: http://revistaseletronicas.pucrs.br/ojs/index.php/porescrito/article/view/15818/0. Acesso em: 25 nov. 2019.

WARTHA, Edson José.; REZENDE, Daisy de Brito. Os níveis de representação no ensino de Química e as categorias da semiótica de Peirce. Revista Investigações em Ensino de Ciências, Porto Alegre (UFRGS), v. 16, n. 2, p. 275-290, 2011. Disponível em: http://www.if.ufrgs.br/cref/ojs/index.php/ienci/article/view/230. Acesso em: 23 nov. 2019.

ZULIANI, Silvia Regina Quijadas Aro. Prática de Ensino de Química e Metodologia Investigativa: Uma Leitura Fenomenológica a partir da Semiótica Social. 2006. 288 f. Tese (Doutorado em Educação) - Centro de Ciências Humanas, Universidade Federal de São Carlos, São Carlos, 2006. Disponível em: Acesso em: 25 set. 2019.

Submetido em: 21 de março de 2020.

Aprovado em: 28 de maio de 2020. 